\title{
Determining the dynamics of coarse bedload transport using passive indirect monitoring: time-dependent variability at event to inter- annual scales.
}

\author{
Peter W. Downs ${ }^{1,}$ and Philip J. Soar ${ }^{2}$ \\ ${ }^{1}$ School of Geography, Earth and Environmental Sciences, University of Plymouth, Plymouth, UK \\ ${ }^{2}$ Department of Geography, University of Portsmouth, Portsmouth, UK
}

\begin{abstract}
The dynamics of coarse bedload transport in rivers is governed by multiple hierarchical factors including catchment-scale controls on sediment production, annually variable hydroclimatic driving of segmentscale sediment supply, and reach-scale factors related to the interaction of hydraulic forces with channel morphology. Exploring hydroclimatic drivers can beneficially utilise passive sensors to record coarse bedload transport over extended time periods and in previously unattainable resolution. For the River Avon (Devon, UK), five-minute coarse bedload frequency data collected using seismic impact plates inherently records the instantaneous variability of bedload transport intensity, patterns of event-scale hysteresis and selective path transport, and the influence of inter-event supply variations. Converting a four-year record of impacts into loads via a probabilistic, data-driven model illustrates the combined influence of hydroclimate and sedimentology on bedload at the inter-annual scale. Despite highly variable water years, the results indicate that 'bar-building flows' consistently achieve the peak efficiency for coarse bedload transport whereas bankfull flows are relatively ineffective. Further, annual sediment rating curves combine both supply and transport limiting phases. Sediment transport forecasting is thus sensitive to both flow year type and antecedent controls on sediment supply, with implications for advancing sustainable solutions in river management.
\end{abstract}

\section{Background}

The dynamics of coarse bedload transport in rivers is frequently explained as a transportlimited phenomenon. This is despite long-recognised evidence for bedload pulsing resulting in anti-clockwise hysteresis [1], understanding that bedload transport rates are always below levels predicted by tractive potential, even in supply-unconstrained settings [2], and clear indications of aquatic habitat impoverishment resulting from bedload supply limitations in dammed, urban and other human-affected channel settings (e.g., [3]). More representatively, coarse sediment transport is governed at multiple, hierarchical levels that include catchment-

\footnotetext{
*Corresponding author: peter.downs@plymouth.ac.uk
} 
scale controls on sediment production, annually variable hydroclimatic driving of river segment-scale sediment supply, and reach-scale factors related to the interaction of hydraulic forces with channel morphology and antecedent conditions. Research into catchment-scale controls on sediment connectivity is benefitting from terrain imaging at high spatial resolutions (e.g., [4]). Sensors for indirect passive recording of coarse bedload transport offer the complementary prospect of exploring time dependencies related to hydroclimatic and channel-scale controls at resolutions previously possible only at select locations with extensive and permanent bedload monitoring infrastructure. Seismic impact plates, a geophone with a binary output signal, offer high temporal resolution measurement of bedload initiation, cessation, intensity over extended time periods. They are relatively inexpensive, portable, non-intrusive and, in our experience, a robust means of monitoring coarse sediment transport. The current study explores hydroclimatic and channel-scale controls using the multi-year results obtained from a three-array installation of seismic impact plates at the mouth of a piedmont catchment in South-west England.

\subsection{Study Area}

The Devon River Avon rises in the southern half of the Dartmoor National Park in South West England (elevation $460 \mathrm{~m}$ ) and flows approximately $40 \mathrm{~km}$ to the sea (catchment area $110 \mathrm{~km}^{2}$ ). Average annual rainfall ranges from 2,200 $\mathrm{mm}$ in the headwaters to $1,000 \mathrm{~mm}$ at the coast. The upper catchment is dominated by igneous granite producing naturally low rates of coarse sediment supply (expect where historical placer mining occurred [5]), whereas the slates, shales and grits that characterise the steep-sided valleys of the mid- and lowerreaches result in a relatively abundant supply of gravel and cobble [6]. The catchment is predominantly rural with grazing in the upper reaches replaced by mixed arable and pasture in the middle and lower reaches; it provides regionally important habitat for salmonid species, notably Atlantic salmon (Salmo salar). The study site sits within a fully alluvial, actively meandering gravel bed channel; such morphology occurs only in the lowest few kilometres of the catchment and the sharp break from gravel-cobble basal bank sediments to the silty loams of the floodplain above may be a response to abundant fine sediment wastes resulting from intensive tin mining in the upper catchment during the 15th and 16th centuries AD (or earlier [7]). The study site has a reach bed slope of 0.0041 and a bankfull water surface slope of 0.0023 , a median surface grain size of $33 \mathrm{~mm}$ and a median sub-surface grain size of 15 $\mathrm{mm}$. Frequent gravel mobility is suggested by convergence of surface and bulk grain size at $\approx$ D60.

\section{Methods}

\subsection{Impact Plates}

Coarse bedload sediment transport has been recorded using three 'Benson type' seismic impact plates operational since April 2012 (IP1 - centre channel) and December 2012 (left and right-hand plates, IP2 and IP3, respectively). The devices, equally spaced across the channel cross-section, consist of a $150 \times 130 \times 6 \mathrm{~mm}$ steel top plate fitted with an accelerometer converting the mechanical energy of the particle strike into an electrical impulse recorded by an integrated datalogger (see [8] for an early version). They are installed flush to the channel bed and mounted on a paving slab for stability, with field and laboratory evidence suggesting that particles $\geq 10 \mathrm{~mm}$ produce a sufficient voltage to be recorded by the plate [9]. The plates record at a maximum of $5 \mathrm{~Hz}$ (to reduce the potential for multiple counts of rolling particles) with the datalogger monitoring sediment movement over 64,000 2.5- 
minute intervals (maximum of 255 counts in each period) before the data logger requires downloading and re-setting. The plates thus provide a near-continuous record of the start, end and relative intensity of coarse bedload movement. Results were compared directly with an agency operated gauging station situated only $1.2 \mathrm{~km}$ upstream of the study site. Flow elevations at the site were recorded using a submersible pressure transducer; several further pressure transducers installed upstream and downstream of the site were used to develop a robust indication of water surface slope at different flow levels. Particle size distributions for the surface and sub-surface fraction of the bedload were established using multiple 'Wolman' particle counts and bulk samples, respectively. The dynamics of the first season of coarse sediment transport are examined in detail in [9]).

\subsection{BedLoad from Impact Plates (BLIP)}

Impact plates count the frequency of transported coarse bedload but do not record particle size. As a remedy, we developed a data-driven, uncertainty-bound, probabilistic method for converting the counted particles into an estimate of bedload. The BedLoad from Impact Plates (BLIP, [10]) approach represents a complementary 'class' of bedload estimation that borrows from both commonplace methods of bedload estimation, that is, from active bedload monitoring and sediment transport predictions (Fig. 1). For each 2.5-minute period (amalgamated to 5-minute periods for computational efficiency), the BLIP model converts individual sediment records into a probabilistic array of possible particle sizes in transit using a Monte Carlo simulation to estimate load based on knowledge of the particle size distribution of the channel bed and local flow levels to establish boundary shear stress above each plate (detailed method in [10]). The approach is thus high-resolution and location-specific and, because the estimate is based on empirical data from the impact plates, it is autogenically moderated for sediment supply and thus less prone to over-estimation than sediment transport equations. The impact plate dataset is also used to internally calibrate the model before each run, optimising for the largest particle in motion at any individual flow against the Shields parameter and sediment hiding coefficient. The Monte Carlo simulation provides an uncertainty-bound, indicative range of bedload estimates that is faithful to the stochastic nature of bedload transport and, being model-based, the approach is amenable to sensitivity testing and thus use in channel design applications.

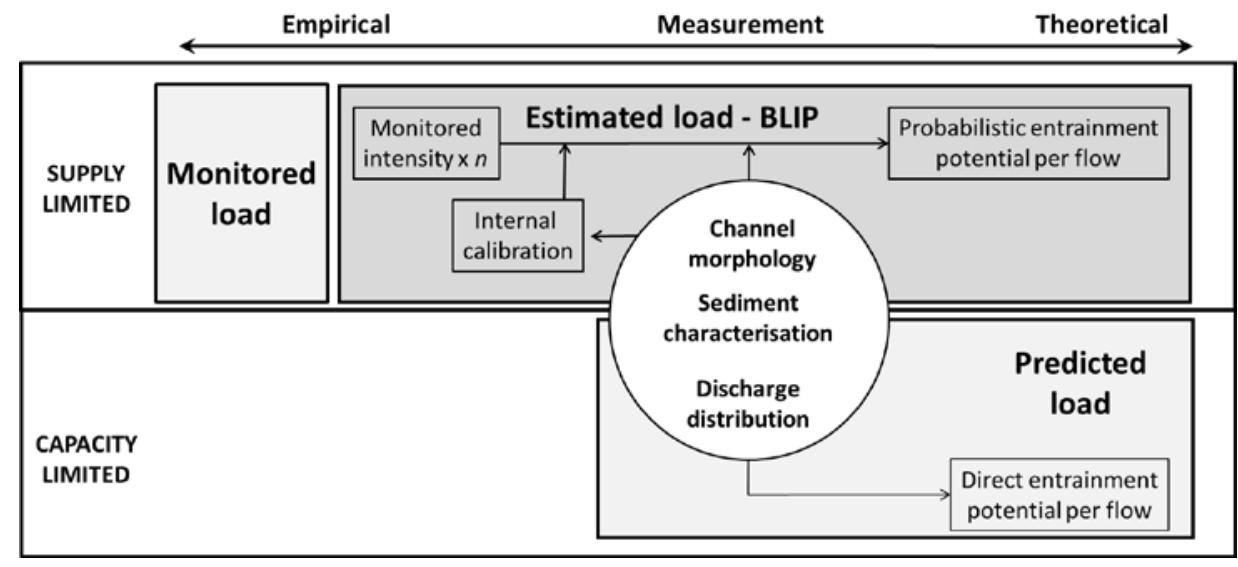

Fig. 1. The BedLoad from Impact Plates (BLIP) approach to bedload estimation, compared to active monitoring of bedload and tractive force-based predictive approaches. 


\section{Results}

\subsection{Bedload dynamics at instantaneous to event-scales}

Time series records from the early monitoring period showed a good general correspondence between high flow events and impact plates counts but the best-fit power relationship $\mathrm{R}^{2}$ of $38 \%$ indicates considerable instantaneous variability. The scatter associated with this plot (Fig. 2) indicated a gradual onset of sediment entrainment followed by rapidly increasing rates of transport peaking at about $15 \mathrm{~m}^{3} \mathrm{~s}^{-1}$, just below the 'barfull' value of $20 \mathrm{~m}^{3} \mathrm{~s}^{-1}$. Rates decrease thereafter until the channel is overtopped $\left(32 \mathrm{~m}^{3} \mathrm{~s}^{-1}\right)$, after which rates slowly increase again.

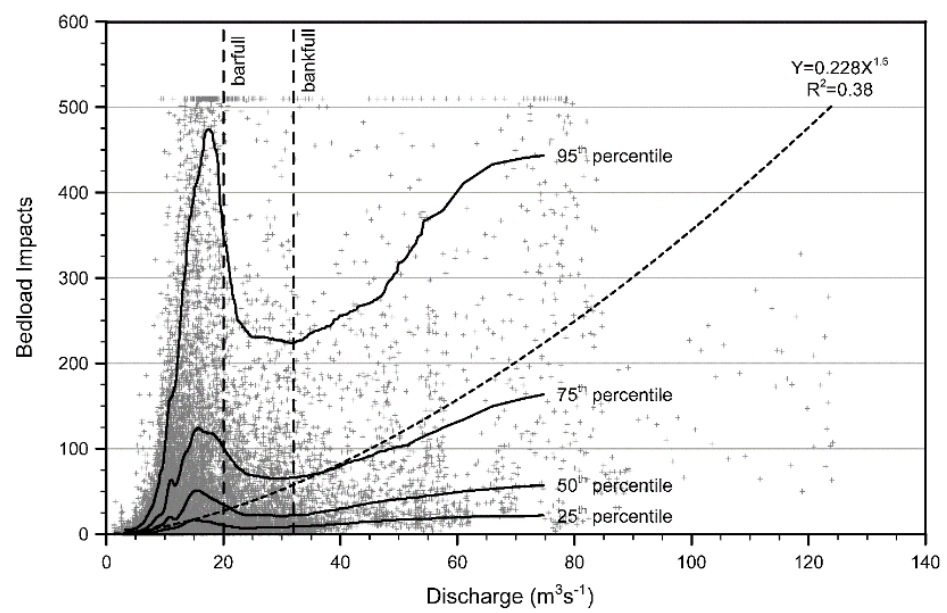

Fig. 2. Instantaneous discharge versus 5-minute impact count totals for the period from late April 2012 to early May 2013. Weighted percentiles based on a moving window through $10 \%$ of the data set and a Gaussian kernel smoothing algorithm highlight the variability of counts with discharge. Source: [9]: Fig. 7. Reproduced with permission of J. Wiley \& Sons.

Detailed exploration of these patterns [9] revealed the following time-dependent general attributes. First, there was significant hysteresis in the instantaneous response of bedload to the passage of a high flow event, with an equal distribution of clockwise and anti-clockwise hysteresis in sub-barfull events giving way to predominantly anti-clockwise hysteresis in over-topping events. We speculate that the smaller rising limb spike relates to locallyavailable material whereas the larger falling limb spike reflects the time-lagged, supplydriven routing of material derived from further upstream. Second, there was considerable inter-event variability in impact counts - for example, one $30 \mathrm{~m}^{3} \mathrm{~s}^{-1}$ event that occurred a week after the flood of record in 2012 resulted in a similar pattern of hysteresis but count rates that were approximately four times those of a $30 \mathrm{~m}^{3} \mathrm{~s}^{-1}$ event that occurred two weeks before the flood of record - also indicating the influence of sediment supply. Third, when the impact counts from 48 discrete events were aggregated and regressed against the event's total volume of flow above the transport threshold (as a surrogate for the total energy supplied by the event), the R2 was $74 \%$. Thus, when considered over event scales (here, averaging 32 hours in duration) there is clearly an additional transport-limiting element to coarse bedload transport which is masking the effect of supply-dominated variability at nearinstantaneous timescales. 


\subsection{Inter-annual variability}

Monitoring of the three-plate array has subsequently encompassed four full OctoberSeptember water years (WY). WY2013 and WY2014 were both 'wet' years but in different ways: whereas WY2013 was punctuated by numerous significant flood events including a 25-year recurrence interval (RI) event, WY2014 produced only a 2-year RI flood event but was the wettest overall year in terms of 'moderately' high flows (i.e., daily mean flows $<30 \%$ flow exceedance). WY2015 was the driest year of the last decade with a peak RI event of 1.2 years while WY2016 was slightly wetter with a 1.7-year RI event. In each case, a similar pattern of instantaneous impacts was observed to those shown in Fig. 2, with the magnitude of counts dependent on the flow year type and the maximum discharge achieved in that year.

Applying the BLIP model to the annual count data (see [10] for approach) suggested a maximum cross-sectional bedload transport rate of between 0.2 and $0.3 \mathrm{~kg} \mathrm{~s}^{-1} \mathrm{~m}^{-1}$ in the wetter years but with a vast majority of flows transporting $<0.15 \mathrm{~kg} \mathrm{~s}^{-1} \mathrm{~m}^{-1}$. In the drier years, transport rates rarely exceeded $0.1 \mathrm{~kg} \mathrm{~s}^{-1} \mathrm{~m}^{-1}$ and were usually $<0.05 \mathrm{~kg} \mathrm{~s}^{-1} \mathrm{~m}^{-1}$. Total coarse bedload discharge (i.e., $>10 \mathrm{~mm}$ ) was estimated to be a maximum of $1860 \mathrm{t}$ in WY2013 bounded by an inter-quartile range (IQR) of 1630-2150 t. The similar total of $1570 \mathrm{t}$ (IQR 1340-1878 t) in WY2014 illustrates a trade-off between a series of significant flood events (WY2013) and a persistence of moderately wet conditions (WY2014). Coarse bedload totals in the drier years were an order of magnitude lower, $180 \mathrm{t}$ (IQR 138-235 t) in WY2015 and $190 \mathrm{t}$ (IQR: 139-271 t) in WY2016. The IQR serves to highlight the stochasticity inherent to sediment transport estimation, even with high resolution data, and the upper limits potentially provide an insight into extreme scenarios of sediment delivery to better inform channel design and management practices.

\section{Discussion}

Converting a four-year record of impacts into loads illustrates the combined influence of hydroclimatic drivers and sedimentological structures on bedload at the inter-annual scale. Despite highly variable water years, high resolution (5-minute) monitoring indicated the persistent dominance of 'bar-building flows' as the peak efficiency for coarse bedload transport and the relative ineffectiveness of bankfull flows (i.e., $\mathrm{Q}_{\mathrm{bf}}$ ). When discharge and bedload are normalised by their values at bankfull, sediment movement peaks between 0.3 and $0.4 \mathrm{Qbf}$, and the overwhelming majority of transport occurs in the range $8-20 \mathrm{~m}^{3} \mathrm{~s}^{-1}$ (i.e., up to 'barfull' stage), irrespective of water year. For this channel, at least, the dominant effect is undoubtedly driven by hysteresis: flows approaching barfull achieve a reasonable magnitude of bedload transport both on the rising and falling limb of the hydrograph, with the falling limb also characterised by a temporally sustained period of transport, especially when following overbank events. The effect is magnified by the greater frequency of barfull flows than those at bankfull and results in a dominant discharge for annual bedload transport at flows below barfull (e.g., 13-15 $\mathrm{m}^{3} \mathrm{~s}^{-1}$, [9]), thus underscoring the dominance of supplylimiting factors on total sediment load.

Second, deriving annual rating curves for bedload transport using a locally-weighted scatterplot smoothing function applied to the percentiles (based on LOWESS [11]) in preference to a linear fit $[12,13]$ provides curves that indicate a combination of both supply and transport limiting phases (approaching barfull, and following overtopping flow, respectively), the balance of which depends on the water year type. Normalising the curves to permit comparison further suggests that the relative magnitude of the 'supply limited bulge' in the rating curve reduces in drier years. The prospects are conceivably that there is 
a progressive reduction in locally available material in the channel thalweg subsequent to the import of significant volumes of material from a relatively large contributing area during extreme flow events, (i.e., supply exhaustion), that there are lower virtual velocities of sediment in drier years which actively restricts the length of channel network providing sediment supply, or that frequent flood events limit channel bed 're-structuring' periods such that wetter years are likely to have greater local supply. This latter result suggests that sediment transport forecasting is sensitive to both flow year type and antecedent conditions that govern the availability of sediment supply, and that there are parallels with temporal notions of geomorphological sensitivity as a function of disturbance frequency and relaxation time [14].

\section{Conclusion}

Passive indirect monitoring of coarse bedload dynamics at high temporal resolution emphasizes that coarse bedload transport is time-dependent at scales that vary from seconds to years, even in this relatively 'sediment rich' setting. Just as research into sediment connectivity has implications for better understanding of sediment production and routing [15], and advances in investigating channel bed structure in relation to hydraulic forcing improve our understanding of 'stress history' controls on reach-scale sediment transport dynamics $[16,17]$, so high resolution monitoring of sediment transport can provide insights into the impact of annually variable hydroclimatic drivers on river segment-scale sediment dynamics. Improved understanding of time-dependent bedload behaviour provides the basis for better appreciating potential supply- and transport-limiting effects on bedload dynamics and has implications for developing sustainable solutions in river management.

Acknowledgements: Instrument installation was funded by a grant from the Seale-Hayne Education Trust to the first author. An exchange programme grant from CONICYT Chile facilitated productive discussions and analyses with Luca Mao and Ricardo Carrillo. We thank Richard Hartley, Alex Taylor and Stephen Haley for field assistance, and Adrian Simpson and John Hosking for permission to access their land. Tim Shipley, Sandy Satterly and Andy Roberts provided gauging station data. The impact plates used here are made by Ian Benson (iandesignandbuild@gmail.com).

\section{References}

1. I. Reid, L.E. Frostick, J.T. Layman, Earth Surf. Proc. Land. 10, 33-44 (1985)

2. B. Gomez, P. Natl. A. Sci. USA 103, 17170-17173 (2006)

3. P.W. Downs, M.S. Singer, B.K. Orr, Z.E. Diggory, T.C. Church, J.C. Stella, Geomorphology, 48, 847-864 (2011)

4. M. Carvalli, S. Trevisani, F. Comiti, L. Marchi, Geomorphology 188, 31-41 (2012)

5. S.B. Bradley, Geoarchaeology 5, 29-41 (1990)

6. S. Twohig, Unpubl. MRes. Diss. Uni. Plymouth UK, (2014)

7. V.R. Thorndycraft, D. Pirrie, A.G. Brown, Geoarchaeology 19, 219-236 (2004)

8. K. Richardson, I. Benson, P.A. Carling, IAHS Publ. 283, 228-235 (2003)

9. P.W. Downs, P.J. Soar, A. Taylor, A. Earth Surf. Proc. Land. 41, 147-161 (2016)

10. P.J. Soar, P.W. Downs, Environ. Modell. Soft. 90,182-200 (2017)

11. W.S. Cleveland, J. Am. Stat. Assoc. 74, 829-837 (1979)

12. D.M. Hicks, B. Gomez, N.A. Trustrum, Water Resour. Res. 36, 1129-1142 (2000)

13. J.A. Warrick, L.A.K. Mertes, L. Washburn, D.A. Siegel, Cont. Shelf Res. 24, 20292043 (2004)

14. D. Brunsden, J.B. Thornes, T. I. Brit. Geogr. NS4, 463-484 (1979)

15. R.J.P. Schmitt, S. Bizzi, A. Castelletti, Water Resour. Res. 52, 3941-3965 (2016) 
16. H. Monteith, G. Pender, Water Resour. Res. 41, W12401 (2005)

17. A.-M. Ockelford, H. Haynes, Earth Surf. Proc. Land. 38, 717-727 (2013) 